DOI: https://doi.org/10.32836/2521-666X/2019-65-30

УДК 336.114

\author{
Савастєєва О.М. \\ кандидат економічних наук, \\ доцент кафедри фрінансів, банківської справи \\ та страхування, \\ Одеський національний університет \\ імені І.І. Мечникова
}

\title{
Savastieieva Oksana
}

Odessa I.I. Mechnikov National University

\author{
ВИКОРИСТАННЯ КОНЦЕПЦІї ДЕТЕРМІНІЗМУ \\ ДЛЯ ПОБУДОВИ МОДЕЛІ СИСТЕМИ РЕАЛІЗАЦЇ̈ ЕКОНОМІЧНОЇ \\ ТА СОЦАЛЬНОЇ ФУНКЦЙ ДЕРЖАВИ В ЧАСТИНІ БЮДЖЕТОУТВОРЕННЯ
}

\author{
APPLICATION OF THE CONCEPT OF DETERMINISM \\ TO BUILD A MODEL FOR THE IMPLEMENTATION OF THE ECONOMIC \\ AND SOCIAL FUNCTION OF THE STATE IN THE BUDGET COURT
}

У статті здійснено ідентифікацію підходів до розуміння сутності концепиії детермінізму як філософської доктрини класичного природознавства у сучасній науковій думиі. На підставі комплексного аналізу понять, що стосуються бюджетної сфери, та використовуючи системний підхід, запропонована модель реалізації економічної та соиіальної функиій держави в частині бюджетоутворення, яку розглянуто крізь призму функиіональних аспектів, які визначає бюджетна політика; організаційних аспектів, основу яких становить бюджетний проиес, та інструментальних аспектів, щчо формуються під дією бюджетного механізму. За допомогою побудови комплексу операцій логічного союзу (кон'юнкиій) з'ясовано, що бюджетні доходи та бюджетні видатки є детермінантами запропонованої системи. Доведено наявність взаємозв'язку, взаємозалежності та взаємозумовленості між компонентами системи та виокремлено їі основні властивості.

Ключові слова: концепція детермінізму, система, детермінанти системи, бюджетна політика, бюджетний процес, бюджетний механізм.

В статье осуществлена идентификаџия подходов к пониманию сущности конщепщии детерминизма как философской доктрины классического естествознания в современной научной мысли. На основании комплексного анализа понятий, касающихся бюджетной сферы, и используя системный подход, предложена модель реализачии экономической и сочиальной функций государства в части бюджетообразования, которая рассмотрена сквозь призму функичональных аспектов, которые определяет 
бюджетная политика; организационных аспектов, основу которых составляет бюджетный процесс, и инструментальных аспектов, которые формируются под действием бюджетного механизма. С помощью построения комплекса операций логического союза (конъюнкиии) установлено, что бюджетные доходы и бюджетные расходы являются детерминантами предложенной системы. Доказано наличие взаимосвязи, взаимозависимости и взаимообусловленности между компонентами системы и выделены ее основные свойства.

Ключевые слова: конщепщия детерминизма, система, детерминанты системы, бюджетная политика, бюджетньй процесс, бюджетный механизм.

In modern conditions, the implementation of strategic directions for solving the problems of ensuring a high level of socio - economic development of national society is possible on the basis of concerted action of state institutions, economic entities and citizens, with the main result of this joint activity is the full satisfaction of the interests of all participants. In the context of this, one of the main places is occupied by budgets of different levels. Given that meeting public needs through the creation of a centralized fund of monetary resources is based on the functioning of the budgetary system and, accordingly, the budgetary mechanism, budgetary policy and budgetary process, research into the theoretical foundations of budgetary formation becomes extremely relevant. In the context of the above, it is necessary to use a systematic approach to the study of the process of realization of social and economic functions of the state in the part that is ensured by creating budgets of different levels. The article identifies approaches to understanding the essence of the concept of determinism as a philosophical doctrine of classical science in modern scientific thought. On the basis of a comprehensive analysis of concepts related to the budgetary sphere, and using a systematic approach, the model of realization of the economic and social functions of the state in the part of budgeting, which is considered through the prism of functional aspects determined by the budgetary policy, is proposed; the organizational aspects that underlie the budget process and the instrumental aspects that are generated by the budget mechanism. By building a complex of logical union (conjunction) operations, it is found that budget revenues and budget expenditures are determinants of the proposed system. The existence of interconnectedness, interdependence and interdependence between the components of the system has been proved, which, in turn, necessitates the use of the concept of determinism. The main properties of the proposed model are separated and characterized. This research creates the basis for the formation of scientificmethodological and practical foundations of the organization of the budget process as a component of the system of realization of economic and social functions of the state in the part of budget formation.

Key words: concept of determinism, system, system determinants, budget policy, budget process, budget mechanism.

Постановка проблеми. В сучасних умовах реалізація стратегічних напрямів вирішення завдань забезпечення високого рівня соціально-економічного розвитку національного суспільства можлива на підставі узгодженості дій державних інституцій, суб'єктів господарювання та громадян, при цьому головним результатом цієї спільної діяльності є всебічне задоволення інтересів усіх учасників. В контексті зазначеного одне з основних місць посідають бюджети різних рівнів. Зважаючи на те, що задоволення суспільних потреб шляхом створення централізованого фонду грошових ресурсів грунтується на функціонуванні бюджетної системи та, відповідно, бюджетного механізму, бюджетної політики та бюджетного процесу, великого значення набуває системний підхід до дослідження процесу реалізації соціальної та економічної функцій держави саме в тієї частині, яка забезпечується шляхом створення бюджетів різних рівнів.

Аналіз останніх досліджень і публікацій. Окремі аспекти функціонування бюджетної системи та іiі складових розглянуто у вагомих наукових дослідженнях О. Василика, В. Дем'янишина, I. Запатріної, М. Крупки, Л. Лисяк, Я. Казюк, О. Кириленко, І. Луніної, А. Лучки, О. Музики, В. Письменного, Н. Савчук, А. Шах В. Опаріної К. Павлюк, Ю. Пасічника, В. Федосова, І. Чугунова, С. Юрія та інших. Проте, незважаючи на значущість та грунтовність наукових здобутків зазначених авторів, слід зазначити, що доцільним є застосування системного підходу для дослідження виконання економічної та соціальної функцій держави в частині бюджетоутворення. Таких підхід доцільно обгрунтувати за допомогою філософської концепції детермінізму. Отже, 
мета статті полягає у побудови моделі системи реалізації економічної та соціальної функцій держави в частині бюджетоутворення на основі використання основних принципів концепції детермінізму, доведення доцільності застосування такого підходу.

Виклад основного матеріалу. Концепція детермінізму представляє собою одну з фундаментальних онтологічних ідей, філософську доктрину класичного природознавства, загальнонаукове вчення про причинність, закономірність, безперечний зв'язок, взаємодію та обумовленість усіх систем, явищ і процесів, що відбуваються в об'єктивному світі. За визначенням Л.Л. Срмолович, детермінізм (від лат. Determino - визначаю) - вчення про об'єктивну закономірність і причинну зумовленість всіх явищ. В основі детермінування лежить положення про існування причинності, тобто про такий зв'язок явищ, за якого одне явище (причина) за певних умов породжує інше (наслідок) [1].

Історично концепцію детермінізма пов'язують 3 іменем П. Лапласа, хоча вже у його попередників, наприклад, Демокрита та Спинози, спостерігалася тенденція ототожнення «законів природи», «причинності» 3 «необхідністю», розгляду «випадковості» як суб'єктивного результату незнання справжніх причин [2]. Застосування принципу доктрини детермінізму у сучасній фінансовій науці надає можливість з'ясувати причинно-наслідкові зв'язки функціонування бюджетного механізму, визначити напрями бюджетної політики та організації бюджетного процесу в контексті необхідності реалізації економічної та соціальної функцій держави в частині бюджетоутворення.

На думку засновника теорії систем Л. фон Берталанфі, система - це комплекс елементів, що взаємодіють; сукупність елементів, що знаходяться в певних відносинах один 3 одним та з середовищем [3]. Отже, реалізацію економічної та соціальної функцій держави в частині бюджетоутворення є цілком можливим представити у вигляді системи. Комплексний аналіз понять, що стосуються бюджетної сфери, став основою терміноло- гічної ідентифікації запропонованої моделі; iï необхідно розглядати крізь призму функціональних аспектів, які визначає бюджетна політика; організаційних аспектів, основу яких становить бюджетний процес, та інструментальних аспектів, що формуються під дією бюджетного механізму. Якщо розглядати запропонованої систему в онтологічному аспекті, тобто в контексті взаємодіючих та взаємообумовлених елементів, вона складатиметься 3 визначених підсистем, які обов'язково повинні знаходитися в процесі безперервної взаємодії, мати тісний взаємозв'язок та бути взаємообумовленими. Результатом впливу системи на розподільчі відносини, що відбуваються у зв'язку з формуванням та використанням бюджетних коштів, є зміни кількісних та якісних параметрів явищ соціально - економічних сфери як основи соціально - економічного розвитку. Таким чином відбувається процес практичної реалізації економічної та соціальної функції держави, спрямованих на вирішення проблем та суперечностей, що при цьому виникають. Якщо розглядати реалізацію економічної та соціальної функцій держави в частині бюджетоутворення як систему, то бюджетний механізм, бюджетна політика та бюджетний процес $є$ підсистемами, функціонування яких $\epsilon$ наслідком необхідності реалізації зазначених функцій держави. При цьому необхідно зауважити, що між зазначеними підсистемами та системою спостерігається співвідношення, що є тотожним співвідношенню філософських дефініцій «частина» та «ціле». Отже, частина завжди є носієм характерних рис цілого, як би є його відбитком, визначається природою цілого, завжди зберігає його певні специфічні риси. Існування частини $є$ можливим лише завдяки існуванню цілого, до якого належить вона, а цілого, навпаки, не може бути без частини. Можливим є встановити процес взаємного перетікання частини в ціле та цілого в частини. Підсистеми реалізації економічної та соціальної функцій держави в частині бюджетоутворення $є$ похідними конструкціями від системи, але не $є$ результатом їі механічного поділу. 
Якщо припустити, що реалізація економічної та соціальної функцій держави $F_{E c S}$ в частині бюджетоутворення $\epsilon$ результатом взаємодії бюджетної політики $P_{b}$, бюджетного механізму $M_{b}$ та бюджетного процесу $P r_{b}$, iї можна представити у вигляді виразу операції логічного союзу (кон'юнкції):

$$
F_{E c S}=M_{b} \wedge P_{b} \wedge P r_{b}
$$

В свою чергу, бюджетна політика як підсистема включатиме такі компоненти, як політика у сфері державних доходів (incomes), iii представимо як $P\left(I_{b}\right)$; політика у сфері державних видатків (expenses) - $\mathrm{P}\left(\mathrm{E}_{\mathrm{b}}\right)$; політика у сфері державного боргу, яка в загальному вигляді спрямована на збільшення бюджетних доходів відповідно до потреб суспільства за допомогою боргових (debt) інструментів, тобто виникають доходи бюджету, які мають запозичений характер - $P\left(D\left(I_{b}\right)\right)$; політика у сфері міжбюджетних відносин, спрямована на перерозподіл (redistribution) бюджетних доходів та видатків або джерел їх формування між рівнями бюджетної системи $-P\left(R\left(I_{b} E_{b}\right)\right)$.

Логічний вираз складових частин бюджетної політики матиме вигляд:

$$
\begin{gathered}
P_{b}=P\left(I_{b}\right) \wedge P\left(E_{b}\right) \wedge \\
\wedge P\left(D\left(I_{b}\right)\right) \wedge P\left(R\left(I_{b} E_{b}\right)\right) \rightarrow 1
\end{gathered}
$$

Бюджетна політика як сукупність окремих компонентів спрямована на якомога більш точне та повне досягнення рівня соціально - економічного розвитку, визначеного прийнятою стратегією, отже $P_{b} \rightarrow 1$.

Використовуючи аналогічний алгоритм, представимо бюджетний механізм як сукупність наступних компонентів - механізм мобілізації доходів $\operatorname{Mob}\left(I_{b}\right)$; механізм використання бюджетних коштів $U_{s}\left(E_{b}\right)$; механізм управління бюджетним дефіцитом та боргом Manag $\left(I_{b} E_{b}\right)$; механізм регулювання міжбюджетних відносин Redis $\left(I_{b} E_{b}\right)$ :

$$
\begin{gathered}
M_{b}=\operatorname{Mob}\left(I_{b}\right) \wedge U s\left(E_{b}\right) \wedge \\
\wedge \operatorname{Manag}\left(I_{b} E_{b}\right) \wedge \operatorname{Redis}\left(I_{b} E_{b}\right) \rightarrow 1
\end{gathered}
$$

Так само представимо бюджетний процес як сукупність таких компонентів:
- складання проекту бюджету $\operatorname{Proj}\left(I_{b} E_{b}\right)$;

- розгляд і затвердження проекту бюджету $C A\left(I_{b} E_{b}\right)$;

- виконання бюджету $\operatorname{Ex}\left(I_{b} E_{b}\right)$;

- підготовка звіту про виконання бюджету $\operatorname{Re}\left(I_{b} E_{b}\right)$, тобто:

$$
\begin{gathered}
\operatorname{Pr}_{b}=\operatorname{Proj}\left(I_{b} E_{b}\right) \wedge C A\left(I_{b} E_{b}\right) \wedge \\
\wedge \operatorname{Ex}\left(I_{b} E_{b}\right) \wedge \operatorname{Re}\left(I_{b} E_{b}\right) \rightarrow 1
\end{gathered}
$$

Якщо представити отримані рівняння у вигляді системи

то отримаємо наочну можливість усвідомити, що результат діяльності системи реалізації економічної та соціальної функцій держави в частині бюджетоутворення $F_{E c S} \epsilon$ функцією підсистем щодо формування бюджетних доходів та визначення і здійснення видатків:

$$
F_{E c S}=M_{b} \wedge P_{b} \wedge P r_{b}=f\left(I_{b} ; E_{b}\right)
$$

Отже, в представленому логічному рівнянні бюджетні доходи та видатки $I_{b} E_{b}-$ аргумент функції, тобто від іiі значення якої залежить значення функції.

Відповідно до концепції детермінізма, визначальні (значущі) чинники (детермінанти) визначають структуру та процес функціонування всіх реальних систем. В запропонованій системі лише дві істотні умови визначатимуть доцільність іiі функціонування: процес акумуляції бюджетних коштів (бюджетні доходи) та процес використання бюджетних коштів (бюджетні видатки). Якщо гіпотетично припустити можливість зникнення хоча б одної з цих умов, функціонування системи реалізації економічної та соціальної функцій держави в частині бюджетоутворення втрачає сенс; а здійснення економічної та соціальної функцій взагалі нівелюється. Отже, бюджетні доходи та бюджетні видатки є детермінантами запропонованої системи; відповідно, кожна підсистема має ті ж самі детермінанти.

Використовуючи системний підхід до дослідження засобів реалізації економічної та соціальної функцій держави в частині бюджетоутворення, візуалізуємо його як сукупність взаємопов'язаних складових (рис. 1). В рамках запропонованої системи необхідно дослідити характер відносин, що 
Науковий погляд: економіка та управління, № 3 (65), 2019

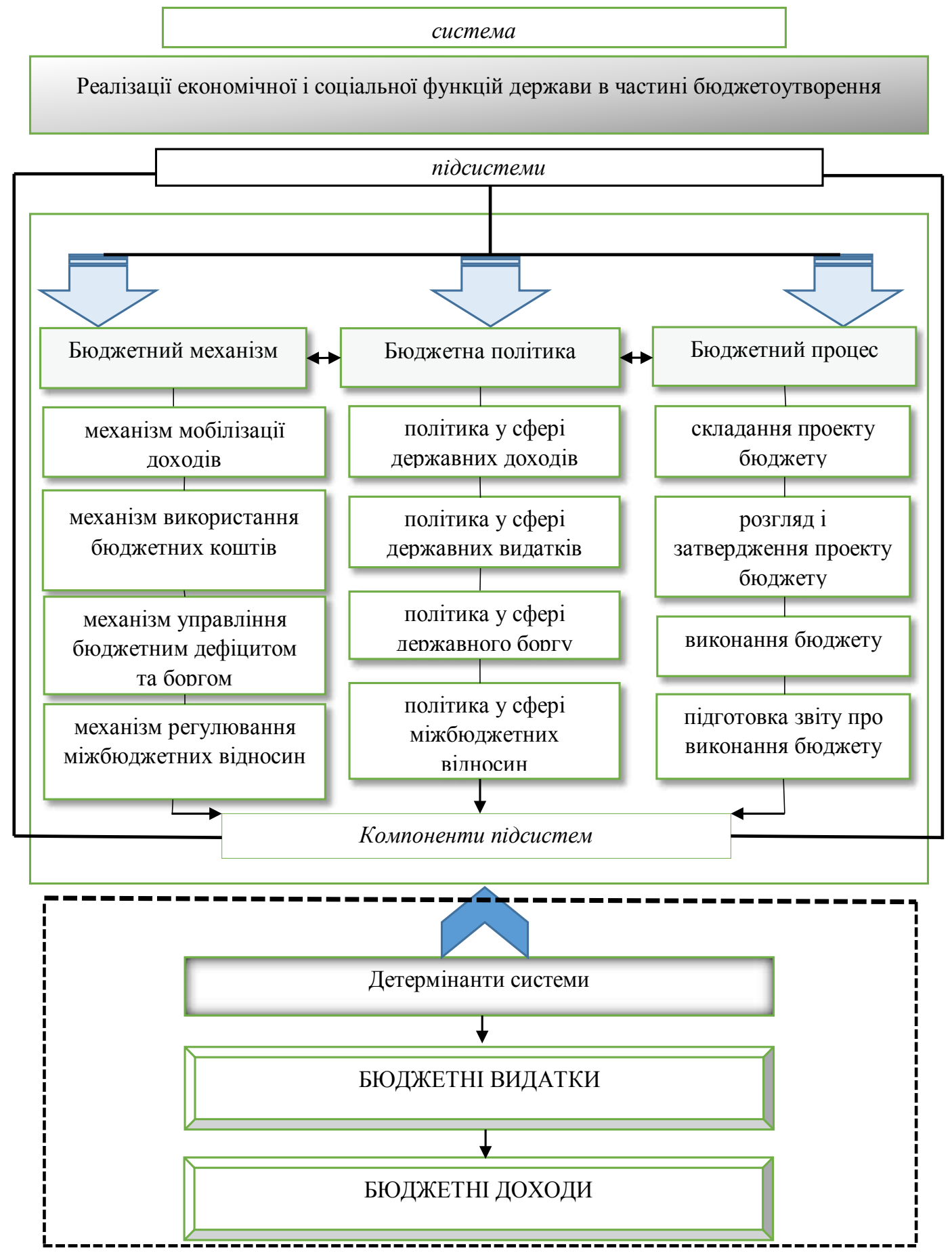

Рис. 1. Модель системи реалізації економічної та соціальної функцій держави та їі детермінанти (концептуальний підхід).

Джерело: побудовано автором 
виникають між її підсистемами. Так, вектори бюджетної політики на кожному конкретному етапі історичного розвитку суспільства наділяють бюджетний механізм особливими специфічними характеристиками, що корелюють 3 пріоритетами бюджетної політики. Абсолютно логічним також вважаємо ствердження, що бюджетний механізм визначає ступень ефективності бюджетної політики, повноту та своєчасність досягнення iï мети; рівень адекватності та ефективності нормативно - правового забезпечення, якість бюджетного планування та бюджетного регулювання, рівень організації міжбюджетних відносин, ефективність бюджетного контролю тощо визначають практичний рівень реалізації бюджетної політики у кожній ланці бюджетної системи. Не повторюючи результати попередніх наукових досліджень [4], [5], [6], зазначимо, що між підсистемами «бюджетний механізм» та «бюджетний процес» простежується чіткий зв'язок, логічність якого проявляється у наступному. На кожній стадії бюджетного процесу застосовується певний набір методів, форм, інструментів, важелів, які належать до складу бюджетного механізму, тобто бюджетний механізм визначає фактичність проходження кожної стадії бюджетного процесу протягом бюджетного періоду, а значить, обумовлює їх ефективність. В свою чергу, хід протікання кожної окремої стадії бюджетного процесу в кожному бюджетному періоді визначає ступінь ефективності застосовуваних методів, форм, інструментів та важелів бюджетного механізму, та, відповідно, доцільність їх застосування в майбутніх бюджетних періодах. Таким чином, можна дійти висновку про те, що між підсистемами в рамках системи реалізації економічної та соціальної функцій в частини бюджетоутворення спостерігається чіткий взаємозв'язок, взаємозалежність та взаємообумовленість, що доводить доцільність застосування концепції детермінізму при побудові даної системи.

Отже, використання системного підходу в даному випадку в онтологічному аспекті філософської точки зору є абсолютно виправ- даним та логічним. Далі необхідно дослідити властивості системи реалізації економічної та соціальної функцій держави в частини бюджетоутворення:

1. Синергічний ефект, під яким слід розуміти ефект, що виникає у випадку, коли властивості запропонованої системи в цілому $є$ набагато більшими, ніж сума властивостей окремих підсистем, іншими словами, це $\epsilon$ додатковим ефектом, що можливо отримати у вигляді перевищення ефекту функціонування системи над сумою ефектів індивідуального функціонування ii підсистем.

2. Пріоритет інтересів системи ширшого (глобального) рівня над інтересами іiі компонентів (ієрархічність). Система реалізації економічної та соціальної функцій держави в частини бюджетоутворення може бути розглянута як складова частина системи вищого порядку - системи функціонування держави, в той час як її підсистеми - бюджетний механізм, бюджетна політика та бюджетний процес $є$ системами нижчого рівня.

3. Емерджентність, тобто наявність у системи в цілому особливих властивостей, які не $\epsilon$ характерними для окремих ii підсистем та компонентів, а також суми елементів, не пов'язаних системоутвірними зв'язками. Це означає, що здатністю досягнути визначений рівень соціально - економічного розвитку суспільства володіє лише система реалізації економічної та соціальної функцій держави в частини бюджетоутворення в цілому, в той час, як ні бюджетний механізм, ні бюджетна політика, ні бюджетний процес, розглянуті окремо, такою спроможністю не володіють.

4. Мультиплікативність - як позитивні, так і негативні ефекти функціонування компонентів в системі характеризуються властивістю множення, а не додавання. Зміна обсягу акумульованих доходів (дохідної детермінанти), або здійснених видатків (видаткової детермінанти) внаслідок зміни інструментарію, форм, методів, важелів бюджетного механізму, або ж внаслідок зміни пріоритетів бюджетної політики, або ж зміни рівня ефективності бюджетного процесу, здійснює вагомий вплив на зміну величини 
ВВП, обсягу золотовалютних резервів, показників платіжного балансу країни тощо.

5. Цілеспрямованість, яка передбачає, що результат діяльності системи - це досягнення певної цілі (мети системи). Мета системи - досягнення визначеного стратегічними орієнтирами рівня соціально - економічного розвитку суспільства.

6. Альтернативність шляхів функціонування та розвитку. Наслідком реалізації функцій держави в соціально - економічній сфері може бути або стимулюючий, або стримуючий вплив на розвиток суспільства.

7. Робастність, яка передбачає здатність системи зберігати часткову працездатність (ефективність) у випадку відмови іiі окремих елементів чи підсистем. Прояв зазначеної властивості системи полягає, наприклад, при виникненні ситуацій, коли мають місце суттєві порушення стадії розгляду і затвердження проекту бюджету, але ж реалізація економічної та соціальної функції відбувається, хоча і значно знижується ії ефективність.

8. Цілісність, що означає первинність цілого по відношенню до частин. Зміна будь-якої підсистеми або компоненту підсистеми впливає на інші підсистеми і на дію системи взагалі, і навпаки, зміна мети функціонуванні системи відображається на ії̈ підсистемах та компонентах.
9. Взаємодія і взаємозалежність системи реалізації економічної та соціальної функцій держави в частині бюджетоутворення із зовнішнім середовищем.

10. Комунікативність, яка визначає факт існування надзвичайно складної системи комунікацій системи із зовнішнім середовищем.

11. Адаптивність, ця властивість $\epsilon$ похідною від попередньої та характеризує прагнення системи до стану стійкої рівноваги, що відображається у постійній адаптацію іiі параметрів до параметрів зовнішнього середовища, які постійно змінюються (слід зазначити, що стан «нестійкості» не завжди виявляється дисфункціональним для системи, в окремих випадках він здатен виступати як підгрунтя для динамічного розвитку).

Висновки. Виходячи 3 викладеного можна зробити висновок, що побудова моделі системи реалізації економічної та соціальної функцій держави в частині бюджетоутворення шляхом використання принципів доктрини детермінізму доводить істинність стверджень, які зазначають, що без процесу акумуляції бюджетних доходів неможливе існування самої держави, адже сучасна держава - це фіскальна держава і тільки за умови наявності бюджетних доходів та, відповідно, видатків, стає можливим виконання державою власних функцій.

\section{Список літератури:}

1. Л.Л. Срмолович, Л.Г. Сивчик, Г.В. Толкач, І.В. Щітнікова, Аналіз господарської діяльності підприємства, Мн., Білорусь: Інтерпрессервіс; Екоперспектіва, 2001.

2. С.А. Лебедев, И.К. Кудрявцев, «Философские проблемы естествознания». Вестник Московского университета. 2005. № 6. С. 3-20.

3. Bertalanffy L.General System Theory: Foundations, Development, Applications / Bertalanffy L. New York, 1968. 289 p.

4. О.М. Савастєєва, «Модель механізму функціонування інституційної архітектоніки бюджетного процесу на місцевому рівні». Економічний форум. 2018. № 3. С. 230-235.

5. O.N. Savastieieva, «Historical aspects of budget processing at local level in Ukraine», II International scientific conference Economy and Society: a Modern Vectors of Development, Part II, April 27, 2018. Leipzig, Germany: Baltija Publishing. 164 p. - pp.73-75.

6. О.М.Савастєєва, «Історія і теорія місцевих фінансів в економічній думці другої половини XIX - початку XX століття». Приазовський економічний вісник. 2018. № 5(10). С. 368-374.

\section{References:}

1. Iermolovych L.L., Syvchyk L.H., Tolkach H.V., Shchitnikova I.V. (2001) Analiz khozyaystvennoy deyatelnosti predpriyatiya [Analysis of the economic activity of the enterprise]. Minsk: Interpresservis; Ekoperspektiva. (in Russian). 
2. Lebedev S.A., Kudriavtsev Y.K. (2005) Filosofskiye problemy estestvoznaniya [Philosophical Problems of Natural Science] Vestnik Moskovskogo universiteta, no. 6, pp. 3-20.

3. Bertalanffy L. (1968) General System Theory: Foundations, Development, Applications. New York. (in English).

4. Savastieieva O.M. (2018) Model mekhanizmu funktsionuvannia instytutsiinoi arkhitektoniky biudzhetnoho protsesu na mistsevomu rivni [Model of mechanism of functioning of institutional architecture of budget process at local level] Ekonomichnyi forum, no. 3, pp. 230-235.

5. Savastieieva O.N. (2018) Historical aspects of budget processing at local level in Ukraine. Proceedings of the II International scientific conference Economy and Society: a Modern Vectors of Development (Leipzig, Germany, April 27, 2018), Baltija Publishing, pp. 73-75.

6. Savastieieva O.N. (2018) Istoriia i teoriia mistsevykh finansiv v ekonomichnii dumtsi druhoi polovyny XIX - pochatku XX stolittia [The History and Theory of Local Finance in the Economic Thought of the Second Half of the Nineteenth - Early Twentieth Centuries] Pryazovskyi ekonomichnyi visnyk. no. 5(10), pp. 368-374. 